\title{
Perbandingan Perilaku Kesehatan Gigi dan Mulut antara Mahasiswa Program Studi Pendidikan Dokter Gigi Unsrat Semester I dan Semester V
}

\author{
Stephanie G. Wowor \\ Vonny N. S. Wowor \\ Christy N. Mintjelungan
}

\author{
Program Studi Pendidikan Dokter Gigi Fakultas Kedokteran \\ Universitas Sam Ratulangi Manado \\ Email: vaniwowor@gmail.com
}

\begin{abstract}
Oral health is still a problem in Indonesia, including in North Sulawesi. Oral health is affected by oral health behavior. Dental students have good knowledge about oral health, therefore, they can become good models for their families and society. Oral health behavior become more positive and better with increasing education. This study was aimed to analyze the difference in oral health behavior between first semester and fifth semester dental students at PSPDG FK Unsrat (Dental Program Study of Faculty of Medicine, Sam Ratulangi University). This was a descriptive analytical study with a cross sectional design. Data were obtained by using questionnaires. Samples were obtained by using total sampling method. Data were analyzed with the Mann-Whitney test to obtain the difference between both groups. The results showed that there were 41 respondents divided into two groups: first semester students and fifth semester students. Both groups had good oral health behavior with an average score of 89.1 for the first semester students and of 98.7 for the fifth semester students. The statistical test comparing the oral health behavior of both groups showed a p-value of 0.001. Conclusion: There were a significant difference in oral health behavior between the first semester and the fifth semester dental students at PSPDG FK Unsrat. The fifth semester students had better oral health behavior than the first semester students.
\end{abstract}

Keywords: oral health behavior, dental students

\begin{abstract}
Abstrak: Kesehatan gigi dan mulut hingga kini masih menjadi masalah di Indonesia, termasuk di Sulawesi Utara. Kesehatan gigi dan mulut dipengaruhi oleh perilaku kesehatan gigi dan mulut. Mahasiswa kedokteran gigi memiliki pengetahuan mengenai kesehatan gigi dan mulut yang dapat menjadi contoh bagi keluarga dan masyarakat. Perilaku kesehatan gigi dan mulut menjadi lebih positif dan lebih baik dengan meningkatnya tingkat pendidikan. Penelitian ini bertujuan untuk menganalisis perbedaan perilaku kesehatan gigi dan mulut antara mahasiswa PSPDG FK Unsrat semester I dan semester V. Jenis penelitian ialah deskriptif analitik dengan desain potong lintang. Data diperoleh dengan menggunakan kuesioner. Sampel penelitian menggunakan teknik total sampling berjumlah 41 sampel yang terbagi dalam dua kelompok yaitu mahasiswa semester I dan mahasiswa semester V. Perbedaan perilaku kedua kelompok dianalisis menggunakan uji Mann-Whitney. Hasil penelitian menunjukkan seluruh mahasiswa pada kedua kelompok memiliki perilaku kesehatan gigi dan mulut yang baik dengan skor rerata pada mahasiswa semester I sebesar 89,1 dan pada mahasiswa semester V sebesar 98,7. Hasil uji statistik perbandingan perilaku kesehatan gigi dan mulut antara kedua kelompok menunjukkan nilai $\mathrm{p}=0,001$. Simpulan: Terdapat perbedaan bermakna pada perilaku kesehatan gigi dan mulut mahasiswa PSPDG Unsrat semester I dan semester V. Mahasiswa semester V memiliki perilaku kesehatan gigi dan mulut yang lebih baik dibandingkan mahasiswa semester I.
\end{abstract}

Kata kunci: perilaku kesehatan gigi dan mulut, mahasiswa kedokteran gigi 
Kesehatan penting artinya bagi kehidupan setiap orang, karena kesehatan dapat memengaruhi kualitas sumber daya manusia. Kondisi tubuh yang sehat akan berpengaruh pada produktivitas sehari-hari. ${ }^{1}$ Kesehatan gigi dan mulut merupakan bagian dari kesehatan tubuh yang tidak dapat dipisahkan satu dan lainnya karena akan memengaruhi kesehatan tubuh secara keseluruhan., ${ }^{2,3}$ Gigi merupakan bagian tubuh yang berfungsi untuk mengunyah, berbicara, dan mempertahankan bentuk wajah, sehingga penting untuk menjaga kesehatan gigi. ${ }^{4}$

Data hasil Riset Kesehatan Dasar (RISKESDAS) tahun 2013 menunjukkan prevalensi masalah gigi dan mulut di Indonesia sebesar 25,9\% dan Sulawesi Utara berada pada urutan ke- 6 dengan prevalensi masalah gigi dan mulut sebesar 31,6\%. Hasil RISKESDAS 2013 juga menunjukkan bahwa indeks DMF-T penduduk Indonesia mencapai 4,6. Selain itu, berdasarkan penelitian yang dilakukan oleh Notohartojo dan Sihombing pada tahun 2013 dengan menggunakan data sekunder dari RISKESDAS tahun 2013 ditemukan bahwa $95,21 \%$ dari total sampel memiliki jaringan periodontal yang tidak sehat. ${ }^{5,6}$

Kondisi kesehatan gigi dan mulut sangat berhubungan dengan perilaku kesehatan gigi dan mulut. Hal ini sesuai dengan pernyataan Notoadmodjo ${ }^{7}$ bahwa salah satu hal yang dapat memengaruhi derajat kesehatan seseorang termasuk kesehatan gigi dan mulut ialah perilaku. Perilaku seseorang mulai dibentuk dengan adanya pengetahuan yang diikuti dengan sikapnya terhadap pengetahuan serta diharapkan diikuti dengan tindakan.

Secara umum mahasiswa kedokteran gigi merupakan sekelompok orang dari berbagai usia dan latar belakang berbeda yang mengenyam pendidikan tinggi sehingga pengetahuan mengenai kesehatan gigi dan mulut yang dimilikinya dapat juga menjadi contoh bagi keluarga dan masyarakat di sekitarnya. Selain itu, sesuai standar kompetensi dokter gigi Indonesia, salah satu kompetensi utama seorang dokter gigi Indonesia ialah memahami konsep perilaku kesehatan individu dan masyarakat di bidang kedokteran gigi. ${ }^{8}$

Perilaku kesehatan gigi dan mulut menjadi lebih positif dan lebih baik dengan meningkatnya tingkat pendidikan. Penelitian yang dilakukan oleh $\mathrm{Kim}$ et $\mathrm{al}^{9}$ melaporkan bahwa sikap dan perilaku menjaga kesehatan gingiva ditemukan berbeda secara bermakna di tingkat pendidikan mahasiswa kedokteran gigi.

Penelitian ini bertujuan untuk mengetahui perbedaan perilaku kesehatan gigi dan mulut antara mahasiswa Program Studi Pendidikan Dokter Gigi Unsrat semester I dan semester V. Perilaku kesehatan gigi dan mulut yang diukur dalam penelitian ini ialah pengetahuan dan sikap mengenai kesehatan gigi dan mulut; keduanya termasuk dalam domain yang membentuk perilaku.

\section{METODE PENELITIAN}

Jenis penelitian ini ialah deskriptif analitik dengan desain potong lintang. Penelitian dilaksanakan di Program Studi Pendidikan Dokter Gigi Fakultas Kedokteran Universitas Sam Ratulangi pada bulan Desember 2018. Populasi penelitian ini ialah mahasiswa Program Studi Pendidikan Dokter Gigi semester I dan semester V tahun ajaran 2018/2019. Sampel diambil menggunakan teknik total sampling, dan dibagi menjadi dua kelompok: kelompok mahasiswa semester I dan kelompok mahasiswa semester $\mathrm{V}$.

Instrumen penelitian yang digunakan yaitu kuesioner yang mengukur perilaku kesehatan gigi dan mulut berdasarkan pengetahuan dan sikap. Pengolahan dan analisis data menggunakan program komputer dan disajikan dalam bentuk tabel.

\section{HASIL PENELITIAN}

Tabel 1 memperlihatkan bahwa pada kedua kelompok responden berjenis kelamin laki-laki lebih sedikit daripada yang berjenis kelamin perempuan.

Tabel 2 memperlihatkan bahwa kelompok usia responden semester I terbanyak pada usia 17 dan 18 tahun sedangkan semester $\mathrm{V}$ terbanyak berusia 20 tahun. 
Tabel 1. Distribusi responden berdasarkan jenis kelamin

\begin{tabular}{lcccc}
\hline \multirow{2}{*}{ Jenis kelamin } & \multicolumn{2}{c}{ Semester I } & \multicolumn{2}{c}{ Semester V } \\
\cline { 2 - 5 } & $\mathrm{n}$ & $(\%)$ & $\mathrm{n}$ & $(\%)$ \\
\hline Laki-laki & 6 & 31,6 & 6 & 27,3 \\
Perempuan & 13 & 68,4 & 16 & 72,7 \\
Total & 19 & 100 & 22 & 100 \\
\hline
\end{tabular}

Tabel 2. Distribusi responden berdasarkan usia

\begin{tabular}{|c|c|c|c|c|}
\hline \multirow{2}{*}{$\begin{array}{c}\text { Usia } \\
\text { (tahun) }\end{array}$} & \multicolumn{2}{|c|}{ Semester I } & \multicolumn{2}{|c|}{$\begin{array}{c}\text { Semester } \\
\mathrm{V}\end{array}$} \\
\hline & $\mathrm{n}$ & $(\%)$ & $\mathrm{n}$ & $(\%)$ \\
\hline 17 & 9 & 47,4 & 0 & 0 \\
\hline 18 & 9 & 47,4 & 0 & 0 \\
\hline 19 & 1 & 5,2 & 4 & 18,2 \\
\hline 20 & 0 & 0 & 15 & 68,2 \\
\hline 21 & 0 & 0 & 1 & 4,5 \\
\hline 22 & 0 & 0 & 2 & 9,1 \\
\hline Total & 19 & 100 & 22 & 100 \\
\hline
\end{tabular}

Tabel 3 menampikan bahwa pekerjaan orang tua dari kelompok semester I sebagian besar sebagai pegawai baik ASN maupun pegawai swasta sedangkan pada kelompok semester $\mathrm{V}$ sebagian besar pekerjaan orang tua ialah ASN.

Tabel 3. Distribusi responden berdasarkan pekerjaan orangtua

\begin{tabular}{lcccc}
\cline { 2 - 5 } $\begin{array}{l}\text { Pekerjaan } \\
\text { orang tua }\end{array}$ & \multicolumn{2}{c}{ Semester I } & \multicolumn{2}{c}{ Semester V } \\
\cline { 2 - 5 } \multicolumn{1}{c}{$\mathrm{n}$} & $(\%)$ & $\mathrm{n}$ & $(\%)$ \\
\hline ASN & 5 & 26,3 & 14 & 63,8 \\
Pegawai & 7 & 36,8 & 0 & 0,0 \\
Swasta & 2 & 10,5 & 3 & 13,7 \\
Wiraswasta & & 5,3 & 1 & 4,5 \\
Pegawai & 1 & & & \\
BUMN & 2 & 10,5 & 1 & 4,5 \\
TNI/Polri & 1 & 5,3 & 1 & 4,5 \\
Guru/Dosen & 0 & 0 & 1 & 4,5 \\
Pendeta & 1 & 5,3 & 1 & 4,5 \\
Petani & 19 & 100 & 22 & 100 \\
Total & & & &
\end{tabular}

Tabel 4 menunjukkan bahwa pendidikan terakhir terbanyak dari orang tua kelompok semester I dan semester V ialah S1.

Tabel 5 memperlihatkan hasil pengukuran perilaku kesehatan gigi dan mulut dari kedua kelompok; semua responden tergolong pada kriteria baik.

Tabel 4. Distribusi responden berdasarkan pendidikan terakhir orangtua

\begin{tabular}{ccccc}
\cline { 2 - 5 } $\begin{array}{c}\text { Pendidikan } \\
\text { terakhir } \\
\text { orangtua }\end{array}$ & \multicolumn{2}{c}{ Semester I } & \multicolumn{2}{c}{ Semester V } \\
\cline { 2 - 5 } & $\mathrm{n}$ & $(\%)$ & $\mathrm{n}$ & $(\%)$ \\
\hline SMP & 0 & 0 & 1 & 4,5 \\
SMA & 6 & 31,5 & 3 & 13,7 \\
D3 & 1 & 5,3 & 1 & 4,5 \\
S1 & 9 & 47,4 & 12 & 54,6 \\
S2 & 2 & 10,5 & 4 & 18,2 \\
S3 & 1 & 5,3 & 1 & 4,5 \\
Total & 19 & 100 & 22 & 100 \\
\hline
\end{tabular}

Tabel 5. Distribusi hasil pengukuran perilaku kesehatan gigi dan mulut mahasiswa PSPDG FK Unsrat

\begin{tabular}{ccccc}
\hline \multirow{2}{*}{ Kriteria } & \multicolumn{2}{c}{ Semester I } & \multicolumn{2}{c}{ Semester } \\
\cline { 2 - 5 } & $\mathrm{n}$ & $(\%)$ & $\mathrm{N}$ & $(\%)$ \\
\hline Baik & 19 & 100 & 22 & 100 \\
Kurang & 0 & 0 & 0 & 0 \\
Total & 19 & 100 & 22 & 100 \\
\hline
\end{tabular}

Hasil skor rerata perilaku kesehatan gigi dan mulut ialah pada semester I sebesar 89,1 sedangkan pada semester V sebesar 98,7. Hasil uji Saphiro-Wilk terhadap normalitas data mendapatkan nilai $\mathrm{p}=0,004$ untuk kelompok semseter I dan $\mathrm{p}=0,000$ untuk kelompok semester $\mathrm{V}$ yang menunjukkan data kedua kelompok tidak terdistribusi normal.

Hasil uji Mann-Whitney antara mahasiswa semester I dan semester V mendapatkan nilai $\mathrm{p}=0,001$ yang menunjukkan perbedaan bermakna pada perilaku kesehatan gigi dan mulut antara mahasiswa semester I dan semester V.

\section{BAHASAN}

Dalam penelitian ini diperoleh gambaran karakteristik responden berdasarkan jenis kelamin, usia, pekerjaan orangtua, dan pendidikan terakhir orangtua. Berdasarkan jenis kelamin persentase tertinggi pada kedua kelompok mahasiswa ialah perempuan yakni sebesar $68,4 \%$ pada mahasiswa 
semester I dan $72,7 \%$ pada mahasiswa semester V. Umumnya perempuan memiliki kebutuhan estetis yang lebih tinggi dibandingkan laki-laki sehingga dapat memengaruhi perilaku dalam menjaga kebersihan gigi dan mulut. ${ }^{10} \mathrm{Hal}$ ini selaras dengan penelitian yang dilakukan oleh Shah et $\mathrm{al}^{11}$ di India yang menunjukkan bahwa perempuan memiliki perilaku kesehatan gigi mulut yang lebih baik daripada laki-laki.

Berdasarkan usia, persentase tertinggi pada mahasiswa semester I ialah usia 17 tahun dan 18 tahun masing-masing sebesar $47,4 \%$, sedangkan pada mahasiswa semester $\mathrm{V}$ persentase usia terbesar ialah usia 20 tahun sebesar $68,2 \%$. Usia dapat memengaruhi daya tangkap terhadap informasi serta pola pikir sehingga dapat memengaruhi pengetahuan dan sikap. ${ }^{12}$

Berdasarkan pekerjaan orangtua, persentase tertinggi pada mahasiswa semester 1 ialah pegawai swasta sebesar $36,8 \%$, sedangkan pada mahasiswa semester $\mathrm{V}$ persentase pekerjaan orangtua tertinggi ialah ASN sebesar 63,8\%.

Berdasarkan pendidikan terakhir orangtua persentase tertinggi pada kelompok semester I ialah S1 sebesar 47,4\%, dan pada kelompok semester $\mathrm{V}$ persentase tertinggi ialah S1 sebesar 54,6\%. Karakteristik pekerjaan orangtua dan pendidikan terakhir orangtua dapat memengaruhi status sosial ekonomi, sehingga mendukung mahasiswa dalam mengakses informasi mengenai kesehatan gigi dan mulut dengan teknologi. ${ }^{7}$

Tabel 5 menunjukkan bahwa mahasiswa semester I dan mahasiswa semester V seluruhnya memiliki kriteria perilaku kesehatan gigi dan mulut yang baik. Kriteria yang baik pada mahasiswa semester I dapat disebabkan karena mahasiswa semester I telah menjalani masa studi di PSPDG Unsrat selama satu semester sehingga telah mendapatkan pendidikan mengenai kesehatan gigi dan mulut baik melalui pendidikan formal maupun melalui keterlibatan dalam kegiatan yang memberikan pengetahuan mengenai kesehatan gigi dan mulut seperti kegiatan Bulan Kesehatan Gigi Nasional. Hal ini sesuai dengan pernyataan Sunaryo bahwa pendidikan diperoleh tidak hanya melalui pendidikan formal saja tetapi mencakup seluruh proses kehidupan individu, berupa interaksi individu dengan lingkungannya, baik secara formal maupun informal. ${ }^{13}$ Setiap orang dapat mengakses berbagai informasi termasuk informasi mengenai kesehatan gigi dan mulut melalui teknologi yang ada saat ini. Mahasiswa dapat memperoleh pengetahuan mengenai kesehatan gigi dan mulut tidak hanya melalui pendidikan formal tetapi juga melalui media yang didukung oleh teknologi yang ada.

Sekalipun data pada Tabel 5 menunjukkan bahwa seluruh mahasiswa baik semester I maupun semester V memiliki perilaku kesehatan gigi dan mulut yang baik namun terdapat perbedaan pada skor rerata yang diperoleh kedua kelompok mahasiswa. Mahasiswa semester V memperoleh skor rerata yang lebih tinggi yakni 98,7 dibandingkan mahasiswa semester I yang memperoleh skor rerata sebesar 89,1.

Berdasarkan hasil uji normalitas menggunakan uji Shapiro-Wilk, kelompok mahasiswa semester I memiliki nilai $\mathrm{p}=0,004$, sedangkan kelompok mahasiswa semester I memiliki nilai $p=0,000$. Dengan demikian dapat disimpulkan bahwa data pada setiap kelompok mahasiswa tidak berdistribusi normal karena nilai $\mathrm{p}<0,05$. Analisis selanjutnya dilakukan dengan menggunakan uji Mann-Whitney karena data tidak terdistribusi normal. Hasil uji Mann-Whitney menunjukkan adanya perbedaan perilaku kesehatan gigi dan mulut yang bermakna antara mahasiswa semester I dan semester $\mathrm{V}(\mathrm{p}=0,001)$. Terdapatnya perbedaan rerata antara kedua kelompok mahasiswa juga menunjukkan bahwa mahasiswa semester $\mathrm{V}$ memiliki perilaku kesehatan gigi dan mulut yang lebih baik diban-dingkan mahasiswa semester I. Hal ini sejalan dengan penelitian yang dilakukan oleh Sharda dan Shetty ${ }^{14}$ di India yang memperoleh perbedaan bermakna antara mahasiswa kedokteran gigi tahun pertama dan tahun terakhir. Selain itu penelitian yang dilakukan oleh Sari $^{15}$ di Fakultas Kedokteran Gigi Universitas Gadjah Mada 
menunjukkan bahwa terdapat perbedaan sikap dan perilaku kesehatan gigi dan mulut di tiap tingkat pendidikan, yaitu mahasiswa tahun keempat memiliki sikap dan perilaku kesehatan gigi dan mulut yang lebih baik dibandingkan dengan mahasiswa tahun pertama.

Perbedaan perilaku kesehatan gigi dan mulut antara mahasiswa semester I dan semester V dapat disebabkan karena perbedaan tingkat pendidikan kedua kelompok mahasiswa. Mahasiswa semester V telah menjalani pendidikan di Program Studi Pendidikan Dokter Gigi hingga tahun ketiga selama lima semester sedangkan mahasiswa semester I berada pada tahun pertama dan menjalani pendidikan selama satu semester. Pendidikan merupakan salah satu faktor yang memengaruhi pengetahuan. ${ }^{16}$ Perilaku seseorang mulai dibentuk dengan adanya pengetahuan yang diikuti dengan sikapnya terhadap pengetahuan. ${ }^{7}$ Hal ini sesuai dengan penelitian yang dilakukan oleh Sato et $\mathrm{al}^{17}$ di Peru yang menunjukkan adanya pengaruh pendidikan di kedokteran gigi terhadap perilaku kesehatan gigi dan mulut mahasiswa kedokteran gigi.

\section{SIMPULAN}

Berdasarkan hasil penelitian ini dapat disimpulkan bahwa terdapat perbedaan bermakna pada perilaku kesehatan gigi dan mulut antara mahasiswa PSPDG FK Unsrat semester I dan semester V. Mahasiswa semester $\mathrm{V}$ memiliki perilaku yang lebih baik dibandingkan mahasiswa semester I.

\section{DAFTAR PUSTAKA}

1. Pedoman Umum Program Indonesia Sehat dengan Pendekatan Keluarga. Jakarta: Kementerian Kesehatan RI, 2016.

2. Oral health worldwide: A report by FDI world dental federation. Geneva: FDI World Dental Federation, 2009.

3. The challenge of oral disease - a call for global action. The Oral Health Atlas (2nd ed). Geneva: FDI World Dental Federation, 2015.

4. Walmsley AD, Walsh TF, Lumley P, Bruke FJ, Shortall AC, Hayes-Hall R, et al. Restorative dentistry (2nd ed). China:
Elsevier; 2007.

5. Riset Kesehatan Dasar Nasional 2013. Jakarta: Badan Penelitian dan Pengembangan Kesehatan Kementerian Kesehatan RI, 2013.

6. Notohartojo IT, Sihombing M. Faktor risiko pada penyakit jaringan periodontal gigi di Indonesia (Riskesdas 2013). Buletin Penelitian Sistem Kesehatan. 2015; 18(1):87-94.

7. Notoadmodjo S. Pengantar Pendidikan Kesehatan dan Ilmu Perilaku. Jakarta: Rineka Cipta, 2008.

8. Standar Kompetensi Dokter Gigi Indonesia. Jakarta: Konsil Kedokteran Indonesia, 2015.

9. Kim KJ, Komabayashi T, Moon SE, Goo M, Okada M, Kawamura M. Oral health attitudes/behavior and gingival self-care level of Korean dental hygiene students. J Oral Sci. 2001;43(1):49-53.

10. Heasman P. Master Dentistry Vol. 1. Philadelphia: Churchil Livingstone, 2003.

11. Shah AF, Naik C, Dany SS, Satpathy AK, Rajput P, Jan SM. Oral hygiene attitude and behavior of dental students in a government college, India. Int $\mathbf{J}$ Prev Clin Dent Res. 2017;4(4):262-4

12. Azwar. Sikap Manusia, Teori dan Pengukurannya (2nd ed). Yogyakarta: Pustaka Pelajar, 2006.

13. Sunaryo. Psikologi untuk Keperawatan. Jakarta: EGC, 2004.

14. Sharda AJ, Shetty S. A comparative study of oral health knowledge, attitude and behavior of first and final year dental students of Udaipur city, Rajasthan, India. Int J Dent Hyg. 2008;6(4):34753.

15. Sari VK. Perbedaan sikap dan perilaku kesehatan gigi dan mulut mahasiswa kedokteran gigi berdasarkan tingkat pendidikan (kajian pada mahasiswa Fakultas Kedokteran Gigi UGM) [Skripsi]. Yogyakarta: Universitas Gadjah Mada; 2013.

16. Mubarak WI, Chayatin N, Rozikon K, Supradi. Promosi Kesehatan Sebuah Pengantar Proses Belajar Mengajar dalam Pendidikan. Yogyakarta: Graha Ilmu, 2007; p. 26-34.

17. Sato M, Camino J, Oyakawa HR, Rodriguez L, Tong L, Ahn C, et al. Effect of dental education on Peruvian 
6 Jurnal e-GiGi (eG), Volume 7 Nomor 1, Januari-Juni 2019

dental students' oral health-related

2013;77(9):1179-84

attitudes and behavior. J Dent Educ. 